\title{
CONVERSACIÓN SOBRE EL VACÍO Y EL CUERPO DESDE EL ÚTERO COMO DISPOSITIVO METAFÓRICO
}

\section{Marcela Cadena Sandoval}

\section{Universidad Autónoma del Estado de México / cadena.marcela@gmail.com}

Arquitecta de profesión y maestra en Estudios Visuales, dedicada a la producción en artes desde 2003; se ha hecho la misma pregunta de distintas maneras durante los últimos años "¿Qué puede un cuerpo?" Ha participado en exposiciones individuales y colectivas en Colombia, México, Ecuador, Inglaterra, Suecia, Italia y España, y ha sido docente en varias instituciones de educación superior en Colombia y México. Actualmente se dedica a la performance, así como a la investigación sobre la relación cuerpo y arte, cuerpo y escritura, y las estrategias de producción-investigación en artes. Se desempeña como docente de la Facultad de Artes de la Universidad Autónoma del Estado de México.

\section{Anel Mendoza Prieto}

\section{Universidad Autónoma del Estado de México / anelesanel@gmail.com}

Artista Visual, Maestra en Estudios Visuales. Le interesa la dimensión artística como forma de vida y como consigna de libertad. Ha sabido sortear las trampas del sistema y aún es pobre. Ha dictado ponencias y participado en exposiciones artísticas colectivas en distintas universidades y circuitos culturales en México, Colombia y España. Sus principales temas de interés son el problema de la forma, el papel de la técnica en el arte, la razón poética, la forma del cuerpo y la forma de la madre en la cultura mexicana. En 2015 fue becaria de una estancia de investigación durante su posgrado en la Universidad de Granada, donde colaboró en un proyecto artístico colectivo con la Universidad de la Sorbona. Desde hace 7 años se dedica a la docencia, al dibujo, al grabado, a la investigación y a su propia historia. 
Cadena M., Mendoza A. [2016] Conversación sobre el vacío y el cuerpo desde el útero como dispositivo metafórico. Calle 14, 11 [19] pp 44-56

\section{CONVERSACIÓN SOBRE EL VACIO Y EL CUERPO DESDE EL ÚTERO COMO DISPOSITIVO METAFÓRICO}

\section{RESUMEN}

Dos autoras cuestionan los conceptos de vacío y cuerpo, al trabajar una fuerte relación con la maternidad, la no maternidad y la angustia. El artículo expone nueve contenidos relativos al cuerpo, entrama distintos ámbitos discursivos, como: el visual, el expresivo, el somático y el conceptual. El cuerpo como objeto de investigación se somete aquí a la confrontación de dos posiciones: una desde el ámbito de las sensaciones llevadas a un plano conceptual, la otra vinculada con la imposición del cuerpo-carne como territorio orgánico que acapara todas las relaciones del sujeto con el mundo. En la forma del texto es evidente la presencia del otro como cuerpo que se discute a sí mismo. El cuerpo es expuesto como dimensión dialógica. El texto está propuesto en los márgenes disciplinares de los estudios visuales, y su desarrollo hace aportaciones a la discusión contemporánea sobre la imagen.

\section{PALABRAS CLAVE}

Corporalidad, vacío, no maternidad, angustia.

\section{PARLKUNA ÑIMA MAN TIASKAPI INTERU CERPO UKUNIMANDA KAACHISPA}

\section{MAILLACHISKA}

Kai iskai warmikuna tapuchinakummi ñima nanatiaskapi chasallata cuerpomanda ninakuna sugkuna llukankuna wambrakuna sugkuna manema pudinkuna wambra llukangapa chimanda ajai Ilakiriska kankuna kai kilkapi parlaku iskun lluraikuna kawachispa uillispa. Antiska parlaspa. Tapuchikun imasami kawankuna kanchanimanda nukanchipa kausai, uerpo- aicha. Tukuikuna ullaspa atun llagta niska. Kilkai kami ruraska allilla tpuchiska- kaawchiska, chasa mailla mailla iachachimi allilla kawwangapa kunaurra ruraikuna.

\section{RIMANGAPA MINISTISKAKUNA}

Nukanchip, ñima, mna wambra iukai, llakiriska.

\section{CONVERSATION ABOUT EMPTINESS AND THE BODY FROM THE UTERUS AS A META- PHORIC DEVICE}

\footnotetext{
ABSTRACT

Two female authors question the concepts of emptiness and body. They study the relationship between the terms: motherhood, no maternity, and anguish. The article shows nine contents being related with the human body, where several discursive items such as visual, expressive, somatic and conceptual are considered. The human body as a research object is contrasted taking into consideration two positions. The first one considers sensations at a conceptual level, and the second one deals with the body-flesh imposition as an organic territory that
} 
encompasses all the existing relationship between the subject and the world. The work additionally shows the other's presence as a corps, which discusses itself. The human body is exposed as a dialogic dimension. As a final point, this work is part of the visual studies discipline, and it considerably contributes to the contemporary discussion on how the image concept is perceived.

\title{
KEYWORDS
}

Corporality, emptiness, no maternity, anguish.

\section{DIALOGUE Ã PROPOS LE VIDE ET LE CORPS D'APRĖS L'UTÉRUS COMME MÉCANISME MÉTAPHORIQUE}

\section{RÉSUMÉ}

Deux auteurs questionnent les concepts de vide et de corps, en travaillant une grosse relation avec la maternité, la non maternité et l'angoisse. L'article expose neuf contenus relatifs au corps, comprend diverses cadres discursifs comme le visuel, l'expressif, le phycologique et le conceptuel. Le corps comme objet de recherche est soumis à la confrontation de deux positions : d'une côté celle des sensations amenées au aspect conceptuel et de l'autre liée á l'imposition du corps comme territoire organique qui monopolise les relations du sujet avec le monde. La présence de l'autre corps que se questionne par soi-même est évident dans la forme du texte. Le corps est exposé dans une dimension dialogique. Le texte est proposé dans le cadre de l'étude visuel et son développement fournit à la discussion contemporaine de l'image.

MOTS CLÉS :

Corporalité, vide, non maternité, angoisse.

\section{CONVERSACT̃̃O SOBRE O VACIO E O CORPO DESDE O ÚTERO COMO DISPOSITIVO METAFÓRICO}

\begin{abstract}
RESUMO
Duas autoras questionam os conceitos de vazio e corpo, trabalharem uma forte relação com a maternidade, a maternidade não e a angústia. 0 artigo expõe nove contidos relativos ao corpo, entrama diferentes âmbitos discursivos, como: o visual, o expressivo, o somático e o conceitual. $\mathrm{O}$ corpo como objeto de investigação se submete aqui à confrontação de duas posições: uma desde o âmbito das sensações levadas a um plano conceitual, a outra vinculada com a imposição do corpo-carne como território orgânico que abarcará todas as relações do sujeito com o mundo. Em forma do texto é evidente a presença do outro como corpo que se discute a si mesmo. O corpo é exposto como dimensão dialógica. 0 texto está proposto nas margens disciplinares dos estudos visuais, e seu desenvolvimento e contribuições à discussão contemporânea sobre a imagem.
\end{abstract}

\section{PALAVRAS-CHAVE}

Corporalidade, vazio, maternidade não, angústia. 


\section{Método}

El método llevado a cabo consiste en una conversación escritural entre las investigadoras. Considerando que ambas provenimos de una formación en artes, hemos desarrollado este artículo bajo la idea de que la escritura en investigación sobre arte y estudios visuales también puede ser susceptible de basarse en principios que funcionan para el arte acción y la performance. A saber: en la performance, el sujeto del enunciado se expone a la interacción, sin dramaturgia, irradia la necesidad de un interlocutor en tiempo y espacio, reitera la presencia del cuerpo como soporte discursivo. El texto como guión general de la acción, como estructura móvil que es susceptible de transformaciones cada vez que la performance se lleva a cabo. Improvisar, dice Bachelard [2014], es unirse al mundo o confundirse con él.

Así también, en la escritura de este artículo hemos sido expuestas la una frente a la otra, demandando, desde lo real afectivo, esa interacción, esa respuesta.

Contrapunteo: 4. m. Cuba y Ven. Acción y efecto de contrapuntear [II cantar versos improvisados].

El método de investigación en el caso del presente artículo, es una red de conceptos, entretejida a partir de la condición efímera de una conversación, donde se muestra lo aleatorio de los discursos; es decir, que con este método queremos dar fuerza a lo provisional del contrapunteo, en oposición al tipo de discurso que pretenda estar cercado con miras a ser permanente.

Debemos este método a la forma en la que inicia Mil mesetas, cuya construcción está argumentada en la introducción [Deleuze, Guattari, 2002, p. 9] como un texto escrito a dúo -un dúo de muchos, "utilizando lo que nos unía, desde lo más próximo a lo más lejano"1 - el método de este artículo también emerge de la necesidad de cuestionar la idea de un Yo autor, para hacer más amplia la noción de autoría hacia un territorio discursivo más fértil, el territorio de la subjetividad en devenir, territorio discursivo opuesto a la concepción unificada de un yo que dice, intercambiada por un esto que ocurre entre decires, o mejor, por lo que nace desde la interacción molecular de no saberes y contradicciones puestas en la danza infinita del desacuerdo.

Cabe decir con respecto al método que este artículo es exactamente concebido como una articulación, es decir, como el resultado de una coyuntura cuyo fundamento estructural es la flexibilidad. Las articulaciones del cuerpo son las uniones de dos huesos. Para decirlo con una metáfora:

1. El anti-edipo lo escribimos a dúo. Como cada uno de nosotros era varios, en total ya éramos muchos. Aquí hemos utilizado todo lo que nos unía, desde lo más próximo a lo más lejano. Hemos distribuido hábiles seudónimos para que nadie sea reconocible [Deleuze, Guattari, 2002, p. 9). una posición teórica, tanto como una simple afirmación empírica son tan firmes o tan frágiles como huesos del cuerpo, lo que les posibilita el movimiento y los hace ser parte de un todo, es su posibilidad de articulación.

En este sentido, cuando decimos que este artículo es una articulación, tratamos de ampliar los límites de la comprensión misma entre dos sujetos. Abundando una vez más en la metáfora de los huesos: partimos de los delicados cartílagos que pueden unir los huesos de dos organismos diferentes, de dos cuerpos teóricos distintos, produciendo así un monstruo de extremidades flexibles, capaz de moverse, capaz también de funcionar en un todo transdisciplinario como lo es el campo de los estudios visuales.

La base de esta articulación no es estrictamente la búsqueda de comprensión como un absoluto incluso posible, sino jugar con toda posible incomprensión que se encuentra implícita en el deseo de comprender, lo impensado en lo pensado. Tomando en cuenta que lo que ocurre en la forma clásica de un diálogo consiste en dejar salir un radio discursivo desde el centro de una idea hasta su periferia. En el rango de la incomprensión, si imaginamos que es circular, por más que los radios del círculo se acerquen uno al otro, su distancia estará salvada por una fracción infinitesimal de incomprensión.

Finalmente, el método de trabajo se basa en una relación entre dos sujetos, y se presenta a manera de discusión. El método es, a la vez una muestra de dos monólogos puestos en oposición, uno frente al otro, a veces indiferentes entre sí, cada uno con su línea discursiva, pero que por momentos mantienen una confrontación, un diálogo. Sin dejar de ser dos líneas discursivas independientes que, en su autonomía, se sostienen como tramas, con fuerza propia, con sus ficciones y sus mitos fundacionales, con sus respuestas autónomas; y que, sin embargo, se ven cada una atravesada por el discurso de la otra, filtradas ambas por la línea que las enfrenta, como un juego de espejos. Puede decirse que gracias a este método, en donde se yergue lo que se oculta frente a lo que se muestra, fue que logramos poner en cuestión los temas que ocupan la discusión.

\section{Conversación sobre el vacío y el cuerpo desde el útero como dispositivo metafórico}

El cuerpo es tomado aquí como un gran ojo cuya percepción es vasta y entrañable. En el cuerpo del ojo hay vistas de distintas naturalezas. Vista vertical de la vulva, por ejemplo, vista del gran párpado horizontal que es la piel misma, inmenso párpado de visión cutánea, sexual. La pupila es un inmenso pozo de negrura luminosa, un agujero uterino del que emerge todo oxímoron. En una idea del cuerpo como ojo, es decir, como un órgano que recibe lo real que gravita, lo real que duele, la visión se vuelve una pregunta sobre lo tangible, sobre lo que tiene pesantez material, sobre lo que incide y moldea nuestro contacto 
con el mundo, anchamente, orgánicamente. Nueve tiempos ocurren en esta puesta en discurso del cuerpo.

\section{El dolor o el "miembro fantasma"}

¿Alguna vez te conté mi parto? Yo me he dado cuenta de que al narrar el parto uno experimenta una morbosidad gozosa, querida, tú me entiendes. Las contracciones comenzaron un martes. El dolor parecía ser un cólico que cada hora brotaba en el cuerpo, iniciando en las caderas y expandiéndose hacia los lados, duraba unos segundos y se calmaba. No es posible localizar ese dolor en una zona particular del cuerpo. Es como si el cuerpo mismo, todo, se volviera un órgano doliente. ¿Tú recuerdas el cólico menstrual? El dolor de la sangre que sale: "Los hebreos pensaban que la sangre es la vida. Debemos descomponer la síntesis, descomponer la vida en nosotros, morir, volver a ser agua" [Weil, 2003, p. 16]. Transformados de sangre en sangre, vamos penetrando en el dolor como el que penetra en la vida. Dolor que abre la vida. Vida a chorros, a torrentes, dolor de salir, de entrar.

Cuando tú hablas, y cuando las mujeres me hablan de su parto, siento que entro en el campo de lo siniestro, eso conocido/familiar que de repente se hace extraño, pero también eso familiar/extraño que parece de repente conocido, me hablas con naturalidad de "algo" que debería saber, pero que, de todas las maneras posibles, me es ajeno. Dices “¿Tú recuerdas el cólico menstrual?”, intentando aproximarme a ese episodio de alumbramiento, con algo que no tiene ninguna importancia para mí, una contracción de muerte no es una contracción de vida, me recuerda lo que no hay, es el pequeño precio que hay que pagar por evadir la condición femenina de la maternidad, mi pequeña y secreta celebración de soledad. No será un reflejo del cuerpo al recordar una contracción; no ocurrirá como si de un miembro fantasma se tratara, como un dolor de algo que estuvo y ya no está más. Cólico como recordatorio del vacío, del desecho.

En el hospital me dieron una pauta para volver: la pauta del dolor. Me explicaron que las contracciones deben estar separadas por intervalos de cinco minutos y deben ser intensas [insoportables]. Qué precisión para medir una sensación, pensé. No hay otra condición del dolor que la de ser inaprensible, inconmensurable. $Y$ es que precisamente, lo único que se podría medir son los intervalos entre su aparición y su desaparición, si acaso se puede describir su intensidad haciendo uso de metáforas y analogías. Pero nada más. Ese dolor me hizo recordar súbitamente ciertas escenas de porno anal. Quizá lo que más llama mi atención del porno anal es la dimensión del dolor, la pregunta por el dolor físico y la capacidad anímica para soportarlo, desearlo o escapar de él.

Por el hecho de que vida y muerte están abocadas apasionadamente a la depresión del vacío, no se revelan más las relaciones subordinadas del esclavo al señor, sino que vida y vacío se confunden y se mezclan como amantes en los movimientos convulsivos del final [Bataille, 1997, p. 33].

Vida y vacío mezclados, puestos en un lugar central: una mujer. Esa convulsión del final es, a la vez, la convulsión del principio. En el parto se tocan reiteradamente la vida y el vacío como amantes en el momento de la copulación. Para hacer coincidir esto con la propuesta de Bataille, la cópula y el parto pueden proponerse como estrategias mecánicas que hacen girar el mundo. En la concepción

Fotografía: Víctor Borrego, 2015.

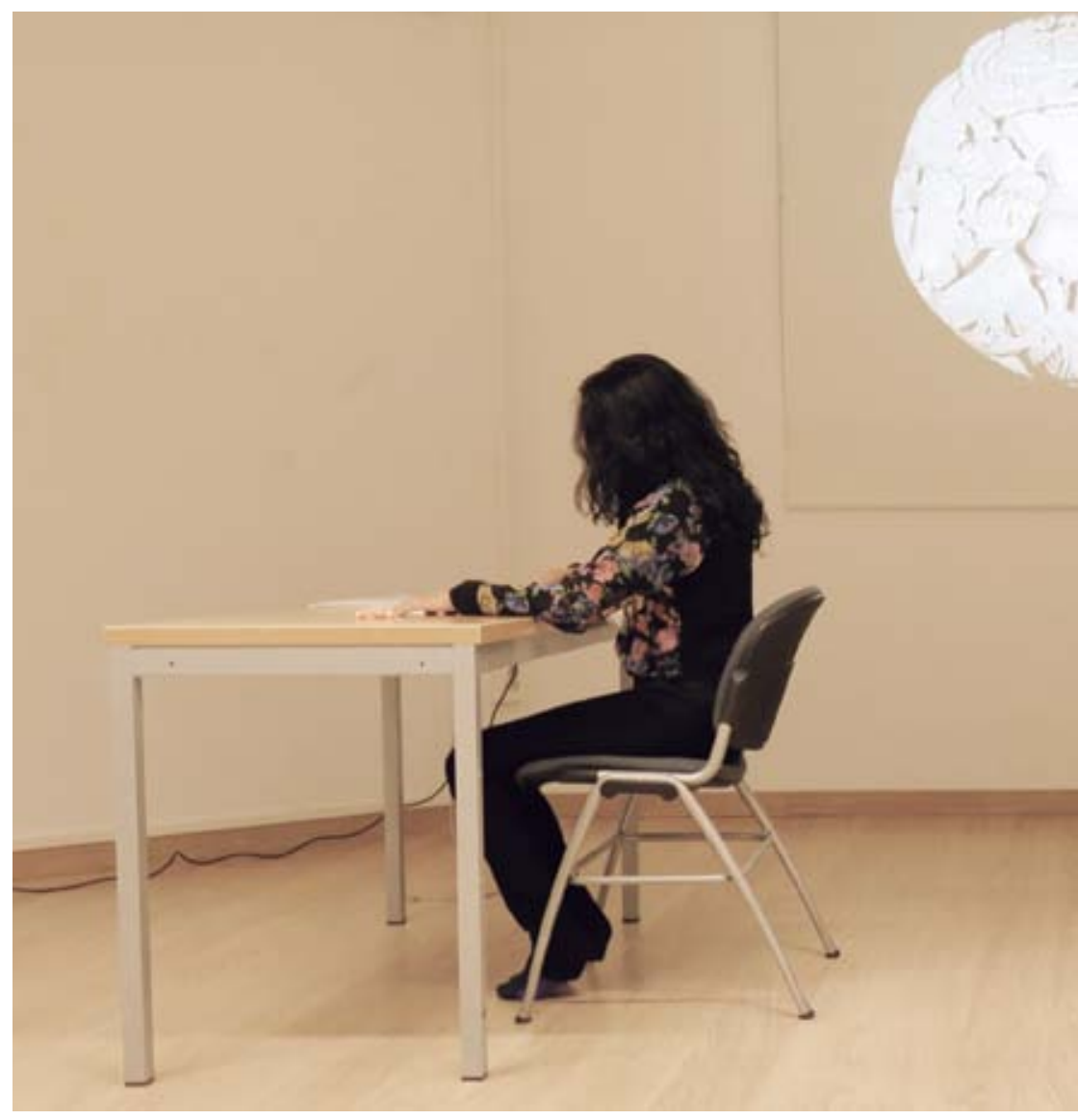

de Bataille ${ }^{2}$ son dos movimientos, la cópula, que es un movimiento de penetración y el movimiento rotativo, giratorio. Esta combinación mecánica orgánica me interesa

2. "Los dos movimientos principales son el movimiento rotativo y el movimiento sexual, cuya combinación se expresa mediante una locomotora compuesta de ruedas y de pistones. Estos dos movimientos se transforman uno en otro recíprocamente. De este modo constatamos que la tierra al girar hace copular a los animales y a los hombres, [como lo que resulta es también la causa de lo que provoca] que los animales y los hombres hacen girar a la tierra copulando" [Bataille, 1997, p. 16]. 
para re-concebir los linderos del cuerpo en su motricidad visual, o, en un decir distinto, re-concebir los aspectos corpóreos de la visión.

\section{El grito o los votos de silencio}

Una vez en el hospital, las enfermeras sugirieron de forma contundente que procurara no gritar, argumentando que el grito le hace daño al bebé. Es quizá la primera vez que enfrenté la consigna real y la máxima desgracia de ser madre: evitar el dolor de otro, de eso que no soy yo aunque salga de mí. Al contarte esto querida, intento acercarme a precisar ese instante del parto como una experiencia del cuerpo en expulsión de sí mismo. Tiemblo de solo recordarlo ¿lo puedes creer? Esa pesantez que exige ser cuerpo, quizá tan evidente en el momento de parir,

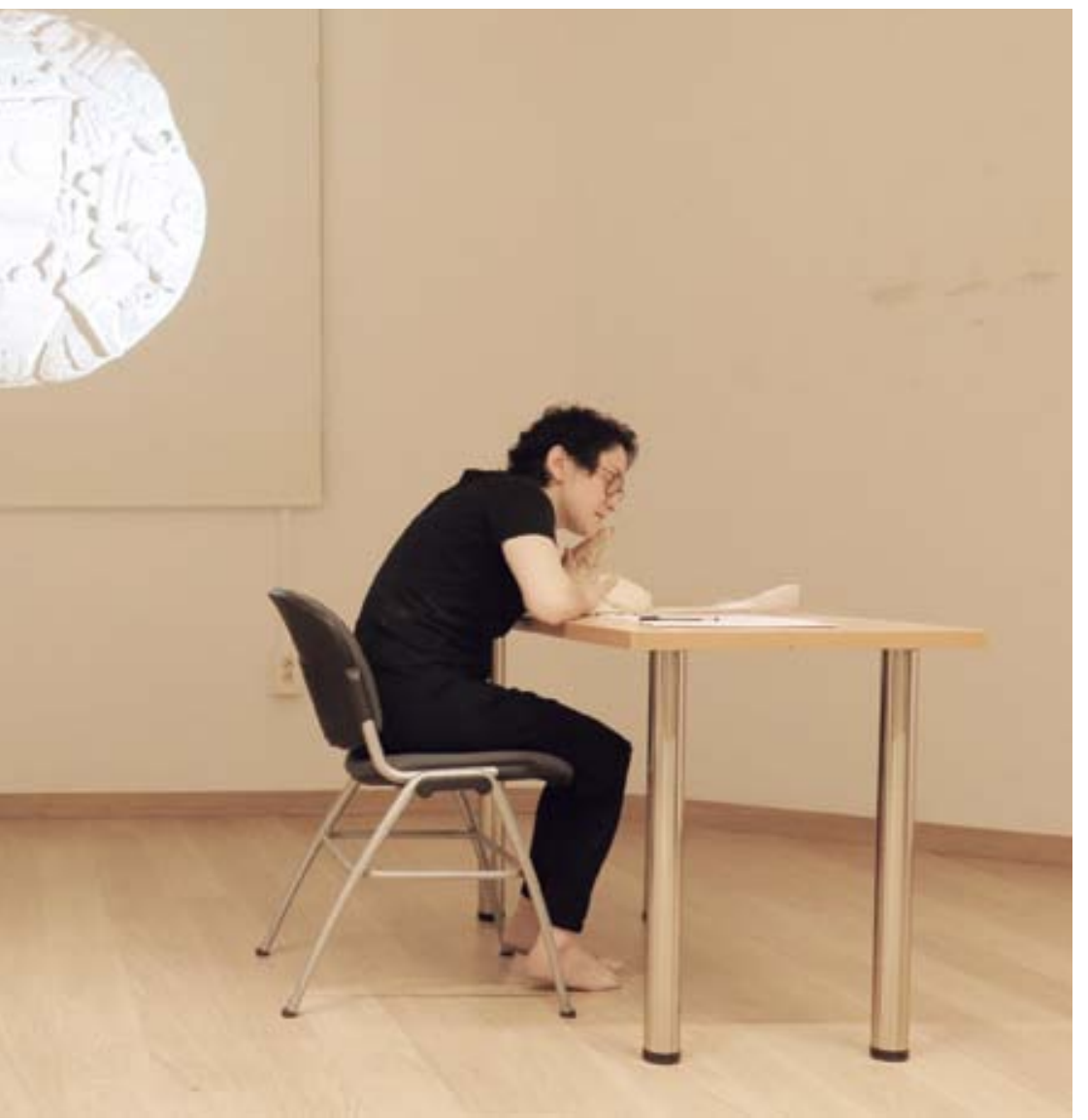

o debo decir, más animal, más real; indescriptiblemente terrorífica, animalidad incontrolable, esa animalidad en la que la muerte no tiene signo. Corporalidad en la que ciertos verbos se agolpan en un mismo instante, y son verbos sin retórica, verbos en los que el lenguaje palidece, se oblitera: penetrar, estirar, distender, contraer, contener, expulsar, salir, escurrir, mojar, doler.

El cuerpo y la teoría me parecen irremediablemente lejanos. Creo que la experiencia será la que supere la teoría, cuantas cosas dice el cuerpo que yo no puedo siquiera traducir en lenguaje para escribir, para plantear una hipótesis esperando encontrar alguna afirmación que me permita entender la corporalidad. El cuerpo como cuerpo-carne está más allá del lenguaje, en esa dimensión que Jacques Lacan llamó de lo "real", en la "cualidad" de Charles Peirce, inaprehensible, buscamos una teoría para entenderlo, pero esta teoría que apliquemos solo alcanzará limitarlo, en un intento por definirlo, por detenerlo, por retenerlo para hacerlo objeto de estudio.

El silencio exigido por esas mujeres es ilógico. Una exigencia adulta, contractual. El cuerpo es un cuerpo niño, en el sentido más amplio. Clarice Lispector describe la desnudez de los monos en un cuento, mientras mira los animales en un zoo. Desnudez insoportable. El mono la mira y ella no puede sostener esa mirada. Si la boca grita es el cuerpo el que grita. El niño es un misterio. El animal. "En el centro del mundo, hay un árbol junto al cual nada produce eco, junto al cual, nada de lo que es perfectamente recto produce sombra" [Weil, 2003, p. 19] ¿Guardar el grito donde el niño no lo escuche? Si sale de mí más naturalmente el grito que el niño. El grito permite salir de mí. Yo no puedo salir de mí. Él no soy yo. Yo nazco con el grito. $Y$ en un grito copula la muerte que escapa del útero, luminosa y oscura, eco del mundo. Al mismo tiempo salen del cuerpo expulsados el grito, el niño, la placenta caliente y un hedor inconcebible. Las perras lamen a las crías para retirarles los restos de placenta.

Y el niño penetra en el mundo, el niño, al nacer, copula con el mundo. El parto es una expulsión por ambos extremos, por ambas cavidades, útero y boca. Pero quiero comparar ese instante con una muerte. Una especie de muerte. En el cine de Gaspar Noe la mujer embarazada es un objeto de angustia $^{3}$. En el filme Enter the void esa angustia palpita de extremo a extremo, de un sueño a un recuerdo, de un recuerdo a un dolor, de un dolor a un órgano doliente, de ahí a un vacío.

Sin embargo, esta revelación del "yo que muere" no se produce cada vez que la simple muerte se revela a la angustia. Supone la perfección imperativa y la soberanía del ser en el momento en que este es proyectado en el tiempo irreal de la muerte [Bataille, 1997, p. 31].

Callar las palabras, como voto de silencio ante la presencia del cuerpo propio, del otro, ante la sensación de no reconocerse, en la deliciosa angustia del extrañamiento. El grito por supuesto sale más fácil, reivindica la existencia y ante eso no hay palabras, ni alumbramientos, ante la abrumadora presencia.

Artaud agobiado ante su cuerpo enfermo, entiende que el lenguaje impuesto como la dimensión simbólica que hace posible el juego del entendimiento entre unos y otros no es suficiente para hablar de su propia presencia corpórea, se deslinda del lenguaje del otro, para hablar en su propio lenguaje, el que emite su cuerpo, ese que no le

3. Entrevista a Gaspar Noe, en el Festival Sitges, 2009. Recuperado de: https: / / www.youtube.com/watch?v=FNvh7WNFmqQ 
puede ser arrebatado y que no puede ser localizado en algún lugar del cuerpo, es cuerpo en tanto dimensión real.

\author{
to feta \\ a to tafura \\ ta fotura \\ e fai ton trumeau \\ ton feta \\ e festa praline \\ to butine \\ y peed las palabras \\ ta rumi \\ to kumi \\ torchati sibiche ${ }^{4}$
}

cuando Artaud escribe-dibuja, canta sus glosolalias, sus 'silabas inventadas'. Su mano, su cuerpo todo [siempre dibujaba y escribía de pie], su voz y aliento, son elementos indisolubles de la única y esencial música de la poesía real producida para ser vista, oída, sufrida, vivida [Cuevas, s.f.].

\section{Los dientes o el súcubo}

Si una muela se cae, se rompe, se desprende de la boca, siempre faltará, es decir quedará un hueco. [La muerte no es un hueco, la muerte es un lleno total, una negrura del ojo con los párpados cerrados. Uno hace el esfuerzo de imaginar esa negrura total con los párpados cerrados y cuesta, porque la luz se interpone, la bruma vital del ojo se hace visible, ahuecando ese lleno total, recortándolo para dejar pasar la luz]. Podremos colocar un implante para la muela, un sustituto. Pero ese sustituto ocupara un espacio siempre inhabitado por su inquilino singular. Así, en la analogía diente-niño, a partir del parto, paroxismo de la vida y la muerte, el hijo me deja vacía.

¿Tú recuerdas una felación, querida? Los dientes deben esconderse en el movimiento de la boca, desde la base del pene hasta la punta. La boca se disfraza de vagina, es el fetiche de la vagina. Pero los dientes están ahí, amenazando. Apretamos la mandíbula cuando tenemos rabia. Apretamos la mandíbula para masticar lo duro. Apretamos la mandíbula para enfrentarnos al dolor. Los dientes son frontera, arma o herramienta. Son una fuerza: "Frontera de los besos serán mañana, cuando en la dentadura sientas un arma. Sientas un fuego correr dientes abajo buscando el centro" [Hernández, 1999, p. 135). A mi hija se le van a caer dos dientes de leche, y algo en su cara, en su expresión ha cambiado notablemente. El inconsciente confunde diente y niño. Dice Groddeck "El diente es el hijo de la boca, la boca es el útero donde se desarrolla, así como el feto se desarrolla en el útero materno" [Groddeck, 1981, p. 54]. De esta idea la vagina tiene una característica en común con la boca: posibilidad de apretar, de contraer, de triturar, de expulsar. Anoche tuve un sueño, anoche soñé que volvía a entrar en la bulimia, me escondía para vomitar, pero no podía, me metía el dedo hasta la garganta [textura parecida a la mucosa de la vagina] solo podía sentir partículas como de arroz en la garganta. No vomitaba, pero en los intentos mi padre me descubría, yo veía su silueta por la ventana del baño [el baño del sueño era un lugar oscuro] y no me decía nada.

El mito de la vagina dentada justifica el paso de la cultura matriarcal a la patriarcal en la cosmovisión suramericana. No recuerdo bien pero, ella siempre daba a luz, ella dio a luz la humanidad, pero esa vagina estaba dentada, hay una relación con el maíz, porque la emborrachan con chicha y como está borracha se queda dormida, entonces llegan los primos y aprovechan que está dormida para partirle los dientes de la vagina ${ }^{5}$.

Piøwachuwø, Um al Duwayce, Lamia, Teimú, Mujer demiurgo, Dama-Vulva, Tlaltecuhtli, Wolunkaa; mujeres, diosas, espectros, súcubos de vagina dentada, con un cuerpo armado que evita la cópula, por lo tanto la concepción.

\section{El útero o el vientre}

-Arrodíllate ¿Cómo te llamas?

-lldegarde

-No, te llamas Sexo. ¿Cómo te llamas?

-Sexo

-No, te llamas Útero. ¿Cómo te llamas?

-Útero

-No, ahora tu nombre es sólo el nombre de la divinidad.

Ya no eres tú misma.

Eres la puerta, el terreno, la corola, la cama de la divinidad.

Giulietta de los espíritus.

Federico Fellini, 1965.

\section{Menstruation at forty}

I was thinking of a son.

The womb is not a clock

nor a bell tolling,

but in the eleventh month of its life

I feel the November

of the body as well as of the calendar.

In two days it will be my birthday

and as always the earth is done with its harvest.

This time I hunt for dead,

the night I want.

Well then

-speak of it!

It was in the womb all along.

Anne Sexton [2013, p. 249]. 


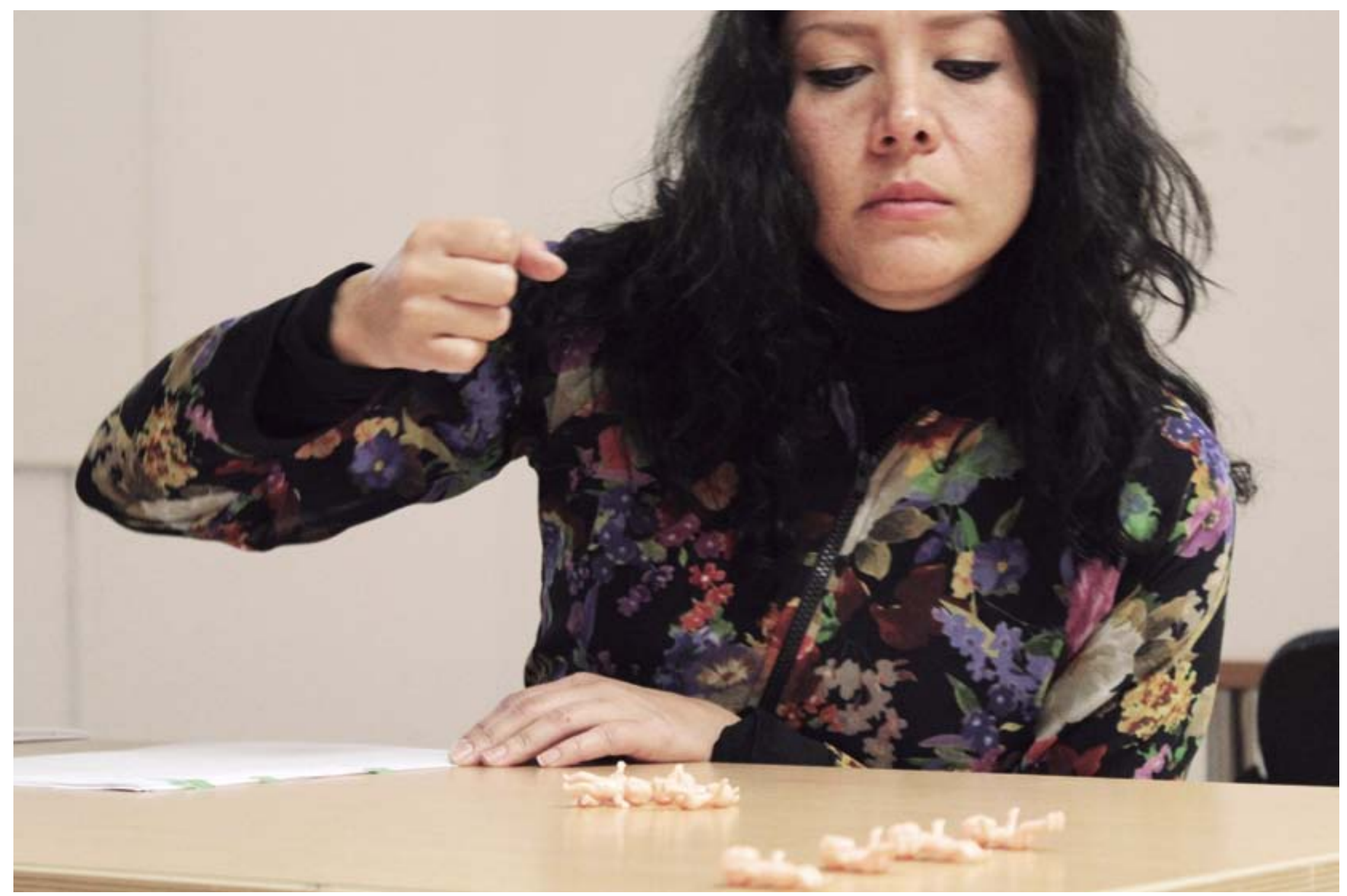

La traducción al español del término womb en este poema da pie para el despliegue de la diferencia entre útero y vientre, el primero en referencia al organismo, el segundo relativo al cuerpo. Womb es un sonido profundo, casi aspirado, un vientre [ven - entre] la posición de la boca para su pronunciación es redonda, womb, los labios se tocan para decir la "b" del final, casi apenas como un parpadeo ["b"] En el libro womb ha sido traducido como "seno" [Sexton, 2013, p. 249]. Cierra los ojos para pronunciarla: womb. Largo y hondo sonido.

\section{El ojo o el vacio}

Ojalá se me pegara el ombligo a la espalda. Ojalá se me borrara el vientre. Ojalá el vacío desapareciera para no llenarse nunca. En mi vientre hay un agujero, hay un espacio imposible, abstracto. En mi vientre hay una dificultad, una No Matriz.

En mi vientre hay un silencio. Si la matriz [no matriz] da forma a lo que contiene, ¿cuál es la forma de mi vacío contenido? ¿Es apropiado hablar de un vacío contenido? De ser así mi vacío tendrá una forma ¿triangular?, como un grifo, que apunta hacia abajo, que chorrea lo que de vida se niega. ¿Es correcto, es apropiado hablar de mi vacío? O yo soy suya.
A Fotografía: Lia Guerrero, 2015.

Respecto del vacío que me posee o el vacío que yo poseo, querida, no son distintos que el de esa hora peligrosa de la tarde [Lispector, s.f.] en la que uno se encuentra sola, desolada, buscando una ficción o una teoría que justifique la existencia de su vientre. Womb. Sabes bien lo que te digo, mujer, esa hora en la que busco un hilo que reúna mi vientre con las cosas del mundo.

Pero yo te pregunto, mujer: ¿No es el vientre un ojo poderoso, un ojo ávido, un ojo intranquilo cuya pupila se dilata más de una vez al mes? Si el vientre es un enorme ojo lo es porque produce realidad. Pero su condición de productor no es virtual o lumínica sino carnal y extensa. El vientre es un enorme ojo miope que produce realidad y adivina, teoriza, especula, genera ficción.

Otra cualidad común entre vientre y ojo: son territorios sin espacio, lugares sin geografía. A diferencia de lo que nos dicen en nuestras clases de anatomía, el vientre no tiene una localización fisiológica específica, sino que está localizado casi abajo del ombligo y hacia adentro, pero también en la boca, entre los dientes -como cuando masticas tus bocadillos maternales, tus diminutos hijos de plástico- y en la glándula pineal, arriba de la cabeza y en la pupila. 
Vientre y ojo no tienen geografía corporal pero sí función orgánica. Es esta condición orgánica del vientre ly la del ojo] una territorialidad espacialmente deslocalizada, que se activa en el tiempo. La Coyolxauhqui, mujer que odiaba a su madre - cosa bastante natural- fue desmembrada por su hermano, descuartizada, dividida, arrojada su cabeza al cielo, mujer dividida en fragmentos, pero cuyos órganos están representados reunidos en un círculo: la luna [¿te suena familiar?], mi madre me decía: siempre andas en la luna m'ija.

Mi madre me cantaba de niña un ritornelo que me sigue como mis ojos a la luna:

Voltea, voltea rueda de fortuna en tu canastilla que parece cuna. Súbeme muy alto, llévame a que vea cómo luce y brilla el lucero blanco.

Parece que ruedas forjando caminos, y al fin nunca llegas hasta tu destino, rueda de fortuna, que alegras la feria súbeme a la luna, bájame a la tierra.

Ritornelo, canción para salir del miedo, teorizado ficcionalmente por Deleuze y Guattari6, ¿lo recuerdas querida?, esa idea de que el agenciamiento territorial no solo es espacial sino a su vez temporal, como el canto del pájaro macho: territorio efímero, sonoro. Del círculo sonoro al cutáneo, del cutáneo al visual. Redondez que regresa. Y ahora me pregunto por el ojo, por la miopía, por eso recurro a una nota que tomé hace días de Groddeck (1999), quien explica algunos métodos de trabajo con personas con trastornos de la visión, haciendo alusión a la teoría de Bates sobre el "esfuerzo y la imaginación", cito:

El paciente debe aprender a ver un plano negro con los ojos cerrados y descansar así el ojo. Bates considera normal que se vea negro con los ojos cerrados y trata de restablecer esta norma con la ayuda de la fantasía del paciente, que debe imaginarse el negro hasta que logre verlo.

¿Tú crees que la pantalla negra imaginada es mía porque yo la creo, o yo soy de ella porque ella me produce a mí? Yo soy una masa borrosa, informe, sin contornos, pero no vacía. Tú preguntas querida: “¿Es correcto, es apropiado hablar de mi vacío?”, y yo te respondo con la visión de la pupila en el espejo: un abismo que me llama, contra el que lucho y ante el cual me doblego, entregándome a su poder. El vacío me traga absolutamente. El vacío me posee a mí, me mancha.

6. "A menudo, se ha resaltado el papel del ritornelo: es territorial, es un agenciamineto territorial. El canto de los pájaros: El pájaro que canta marca así su territorio. [...] El ritornelo puede desempeñar otras funciones, amorosa, profesional o social, litúrgica o cósmica: siempre conlleva, tiene como concomitante una tierra, incluso espiritual, mantiene una relación esencial con lo Natal, lo Originario" (Deleuze, Guattari, 2002, p. 319).
Mientras que el cuerpo es todo ojo, la luz lo atraviesa del nadir al cenit, de abajo hacia arriba, de la tierra al cielo, la luz no está delante de el ojo sino en un constante a través de el ojo, que es el cuerpo. Pero el hijo dificulta el paso de la luz como una puerta, el hijo es frontera, lo mismo que el diente.

Porque el cuerpo rebasa al ojo. Aún con toda su grandilocuencia, la visión es una de las dimensiones que el cuerpo sabotea. Por eso me interesa el párpado cerrado, porque oblitera la salida del ojo y lo devuelve a su dimensión corporal. El párpado es el sistema que posibilita la producción de un vacío que me hace acceder a esa pantalla negra imaginada, que no es ausencia de luz. Aquí me detengo y te pregunto: ¿puede el cuerpo tener un vacío? No lo sé. ¿No crees que "vacío corporal" es una proposición contradictoria?

¿Es contradictorio sentir que cargas un vacío en tu interior? Me interesa lo que de contradictorio tiene la afirmación que te propongo "Estoy llena de falta" y para albergar esa falta tendría que existir una suerte de espacio posible. Un espacio sin coordenadas definidas, que no puedo asegurarte que esté entre el hígado y el páncreas, en los pulmones, o en un óvulo muerto que es expulsado por la vagina. La falta se alberga en el vientre, en la idea de vientre y se siente allí, por ahí, pero no sé exactamente en dónde. Reafirmo que estoy llena de falta, no de vacío.

En el centro del ojo hay un vacío que me posee en la medida en que puedo construirlo. Si antes dije que el útero es un ojo enorme, ahora, con esta pantalla negra que es a la vez cuerpo vacío, digo: el ojo es un útero vacío. El vacío no puede estar a la intemperie. ¿Un vientre vacío o un vientre al vacío? "Ojalá se me pegara el ombligo a la espalda. Ojalá se me borrara el vientre. Ojalá el vacío desapareciera para no llenarse nunca." Y así tener un vientre al vacío, en donde la ausencia no exista, no esa ausencia que presupone un dolor, porque de hecho no habría espacio ni siquiera para la falta.

De niña tenía por costumbre, en esas tardes de vacaciones y domingos, leer algunas páginas del diccionario para encontrar palabras que al no conocer antes, no me importaba su significado hasta que las leía por primera vez. Cuando me aburrí del Pequeño Larousse llustrado de pasta roja, pasé a la Enciclopedia Salvat, y de ahí a la Enciclopedia de Historia del Círculo de Lectores y aunque no las revisaba en orden alfabético como el Autodidacta de La Nausea de Sartre, y permitía que un poco de suerte dirigiera mi conocimiento, lo que quedaba manifiesto, era el resto de enciclopedia que no alcanzaría a leer.

Aún hoy, aunque ya no hace parte de mis hobbies dominicales, reviso el diccionario RAE en línea, un impulso [será) de desconfianza respecto a lo que creo que son las palabras y lo que en verdad las palabras [parece que] son.

\section{vacío, a.}

(Del lat. vacivus). QUIERE

2. adj. Dicho de una hembra: Que no purede tener cría. 
Pero mientras buscaba el significado de la palabra vacío no dejaba de pensar en los aproximados tres minutos de oscuridad que anteceden a la secuencia inicial de 2001: A Space Odyssey, de Kubrick, tres minutos eternos, que parecen un error, una falla, 180 segundos, unos más unos menos, en los que algo falta; hasta que la alineación Luna, Tierra y Sol y la composición Así hablo Zarathustra de Strauss nos sacan de la incertidumbre.

Vientre obscuro, 30 años ya, 31, 32, 33, 34, 35, 36, 37 años eternos, que parecen un error, una falla, 310 óvulos, unos más unos menos desperdiciados, en los que algo falta.

\section{El cuello o las coordenadas 0,0,0}

Ahora, mujer, me hiciste recordar mi cuerpo. Una importante condición somática del útero es que tiene un cuello, el cuello del útero conecta la vagina con el útero. Yo no alcanzo a tocarme el útero con los dedos, es casi tan abstracto como tratar de imaginar mis intestinos. Sabemos de su existencia gracias al dolor, pero no lo podemos tocar. Dentro y oscuro, intangible e invisible.

Como si solo pudiéramos tocar lo que gusta ser tocado, la vagina como acceso a lo profundo del cuerpo, el cuello del útero como frontera para no reconocernos como organismos, cuerpo sin órganos.

\section{El cuerpo es el cuerpo \\ Está solo \\ Y no necesita de órganos \\ El cuerpo no es jamás un organismo \\ Los organismos son los enemigos del cuerpo}

[Artaud, citado por Gilles Deleuze y Félix Guattari, 2002, p. 33].

La luz es una acción por contacto, dice Merleau-Ponty, cuando alude a la Dióptrica de Descartes [2013, p. 33] desarrolla el tema de la luz y la visión: "tal como la acción de las cosas sobre el bastón del ciego". Hay un atrevimiento en esa idea de las cosas actuando sobre el bastón del ciego, esa inversión activa sobre lo que ve tocando, pues no es la visión una posibilidad de puenteo del mundo al pensamiento, sino una extensión de las cosas en su manera de grabarse, de incidir en el cuerpo: "el alma piensa según el cuerpo, no según ella misma” [Descartes, 2013, p. 33).

De acuerdo con esta línea de sugerencias fenomenológicas querida, la visión está apoyada, sostenida por incidencias corporales, por los indicios que el cuerpo ancla en su doble capacidad, la de tocar y tocarse. Como los dedos dentro de la propia vagina [¿es la vagina la que se traga los dedos?], como la lengua acariciando una úlcera de la propia boca [¿es la úlcera la que molesta a la lengua?]. El cuerpo es universo penetrable, mucosa pletórica de escarificaciones y penetraciones. Pero el útero no lo puedo tocar. Mis hijos conocen mi útero y yo no. Todo eso que se expulsa en el parto, esa masa coloidal, caliente y hedionda.
Un cuerpo es una imagen ofrecida a otros cuerpos, todo un corpus de imágenes que pasan de un cuerpo a otro, colores, sombras locales, fragmentos, granos, aureolas, lúnulas, uñas, pelos, tendones, cráneos, costillas, pelvis, vientres, meatos, espumas, lágrimas, dientes, babas, fisuras, bloques, lenguas, sudores, licores, venas, penas y alegrías, y yo, y tú. [Corpus, Jean-Luc, 2003].

Así es, mujer, la imagen del cuerpo como la clave de la perplejidad humana convoca, desde su visceralidad, a lo divino. El cuerpo no es sino el órgano en bruto, con sus conexiones y su función respecto del cosmos, respecto de lo indefinido. Consistencia de tierra húmeda, salada, ferrosa, el vientre es vulnerable por los ecos de lo que nunca se vulnera, de lo que es invulnerable al tiempo, inmaculado por poder alguno. Demoniaco y sublime. Simone Weil dice: "Deseo sensual y belleza. Necesidad de quebrar la impureza interior contra la pureza. Pero lo mediocre en nosotros se defiende para preservar su vida, y tiene necesidad de manchar la pureza. Adquirir poder sobre él es manchar. Poseer es manchar" [2003, p. 16] Inmaculada: con un vacío colocado en el centro de la tierra, que evoca el lugar donde no hay nada. En el centro del círculo que está a la vez en todas partes. Ella hunde sus manos. Ella vuelve a ser flujo. Ella no es.

\section{El pene o el otro}

$$
\text { "At night, alone, I marry the bed"7 }
$$

¿Recuerdas esa fascinación por un pene erecto y esa curiosidad, esa duda, cuando eras niña? ¿Recuerdas haber intentado mear de pie? ¿Son los dedos pequeños penes? Las palabras no penetran. Son penetradas. Son una masa. Tentación de penetrar, de hundir los dedos. Toda ella es penetrable, más allá de sí misma y del lenguaje. Los dedos penetran en las coyunturas que llegan al final del lenguaje, en el borde del sinsentido.

\section{El ombligo o la madre de Alain}

\author{
"Alain medita sobre el ombligo" \\ [Kundera, 2014].
}

Tuve un sueño hace años, era casi una niña, aún lo recuerdo estremecida: estaba yo desnuda, mirando mi cuerpo, la piel alrededor de mi ombligo, mis piernas, no tenía vello púbico. Metí el dedo en el ombligo, y parecía una masa blanda. Pude meter toda la mano, más profundamente. Todo el brazo estaba dentro de mí hasta el codo, como en una masa de pan cruda. No había dolor, más bien curiosidad infantil. Al sacar el brazo estaba bañado en sangre.

\footnotetext{
“¿Y no has pensado en casarte, en tener hijos?

¿Para cuándo los niños?”

"Los hijos son una bendición de Dios"

"Los hijos son la razón de ser del matrimonio"
} 
"La mayor realización de una mujer es ser madre" "Que triste no tener quien te cuide cuando seas viejo" "El tiempo pasa, cuando seas vieja me darás la razón" "una sola no es nadie"8.

"Todos los hijos vienen con un pan bajo el brazo"

La primera vez que se sintió atraído por el misterio del ombligo fue cuando vio a su madre por última vez.

[...] Ha olvidado lo que se dijeron, aunque retiene en su memoria, grabado con precisión, un instante, un instante concreto: sentada en su silla, ella miró intensamente el ombligo de su hijo [Alain]. Él aún siente esa mirada en su vientre. Una mirada difícil de comprender; le parecía que expresaba una inexplicable mezcla de compasión y desprecio; [...]. Nunca más volvió a verla [Kundera, 2014].

\section{Ecografía o el cuerpo más allá de lo visible}

Nine - Nein a oídos poco entrenados, o mal intencionados nine [9] en inglés y nein [no] en alemán suenan prácticamente igual. Como si la fonética de dos palabras en dos idiomas diferentes me dijera algo, un mensaje que subyace, pero que puedo entender con absoluta claridad: Nueve-No.

Desde la creencia de la vagina dentada, esa que no permite el goce masculino, el coito y por lo tanto no sería posible la procreación. Desde el símil de labios bucales y labios vaginales. Aberturas receptoras, que engullen, aberturas que vomitan y excretan. Realizo la acción de masticar por nueve minutos a un pequeño bebé plástico, en un acto de negación a la fertilidad, al contenedormujer, a ceder, a la entrega. El registro de la acción se realiza en un consultorio de gineco-obstetricia a través de una ecografía bucal externa.

Nueve minutos de reafirmación del No. Es el nueve de la espera deformante. El nueve se abre paso. En una de mis notas, ayer, escribía para ti: "abrir paso, acción del esfínter, en la que se combinan la fuerza torrencial de la luz y la fuerza corporal del esfínter". Nueve: una cabeza, dos pezones, una vagina, una boca, un ano, dos pupilas, un cuello. El tres multiplicado por tres. El triángulo invertido del útero. Nueve no.

\section{Conclusiones}

Este texto rescata la epístola y el diálogo como métodos para la construcción de teoría del arte y de la imagen.

El diálogo confesional constituye el soporte expresivo artístico de este ejercicio de investigación.

Los contenidos expuestos en esta relación escritural tienen distintas naturalezas, de manera tal que el artículo es una trama de conceptos y sentires que se conectan para formular un discurso híbrido, apuntando hacia la teoría de la imagen como campo disciplinar en el que pueden atravesarse distintas fuentes teóricas y distintos modos de aproximación de un objeto de estudio.

Concluimos que la maternidad y no maternidad del cuerpo, desde el útero como concepto detonante, no tiene una sola salida.

Esta propuesta abre nueve posibles lugares para continuar discursando las preguntas sobre el cuerpo, y su relación expresiva o artística con respecto al vacío como concepto que pone en reunión lo somático con lo anímico.

Cada uno de los nueve apartados constituye una propuesta de divergencia conceptual sobre el tema del cuerpo.

Cada uno de los nueve temas abordados es una vertiente inconclusa de la discusión sobre la maternidad y la no maternidad, desde el arte como base expresiva y como campo teórico.

Está presente la dimensión del silencio en este diálogo. Como en cualquier conversación siempre hay uno que calla más que el otro. Estos silencios, zonas de vacío, elipsis epistolares han hecho que, en ciertos momentos, el texto se vuelva la exposición de dos monólogos.

\section{Referencias}

Bachelard, G. [2014]. La intuición del instante. México: Fondo de Cultura Económica.

Bataille, G. [1997]. El ojo pineal. Precedido de El ano solar y Sacrificios. España: Pre-textos.

Cuevas, J. [s.f.]. Frenesi de lo visible, glosolalia/ cuerpo-sinórganos: Artaud. Recuperado de: http:/ / www.psicomundo. com/mexico/artefacto/glosolalias.htm

Deleuze, G., y Guattari, F. [2002]. Mil mesetas. Capitalismo y esquizofrenia. España: Pre-textos.

Fellini, F. [1965]. Giulietta degli spiriti. [Película]. Italia, Francia, Alemania. Rizzoli Film. Francoriz Production. Federiz. Eichberg-Film GMBH. [DVD].

Greenaway, P. [1989]. El cocinero, el ladrón, su mujer y su amante. [Película]. Reino Unido, Francia. [DVD].

Groddeck, G. [1999]. La vista, el mundo del ojo y ver sin ojos. España: Gráficas La Paz.

Hernández, M. [1999). Las nanas de la cebolla. (Poesía). Barcelona: Plaza \& Janés Editores. 
Jean-Luc, N. [2003]. Corpus. Madrid: Arena Libros.

Kundera, M. [2014]. El mito de la insignificancia. México: Tusquets Editores.

Lispector, C. [s.f.]. Amor. Cuentos. Ciudad seva.

Merleau-Ponty, M. [2013]. El ojo y el espíritu. Madrid: Editorial Trotta.

Sexton, A. [2013]. Poesía completa. España: Linteo.

Weil, S. [2003]. El conocimiento sobrenatural. Madrid: Editorial Trotta. 


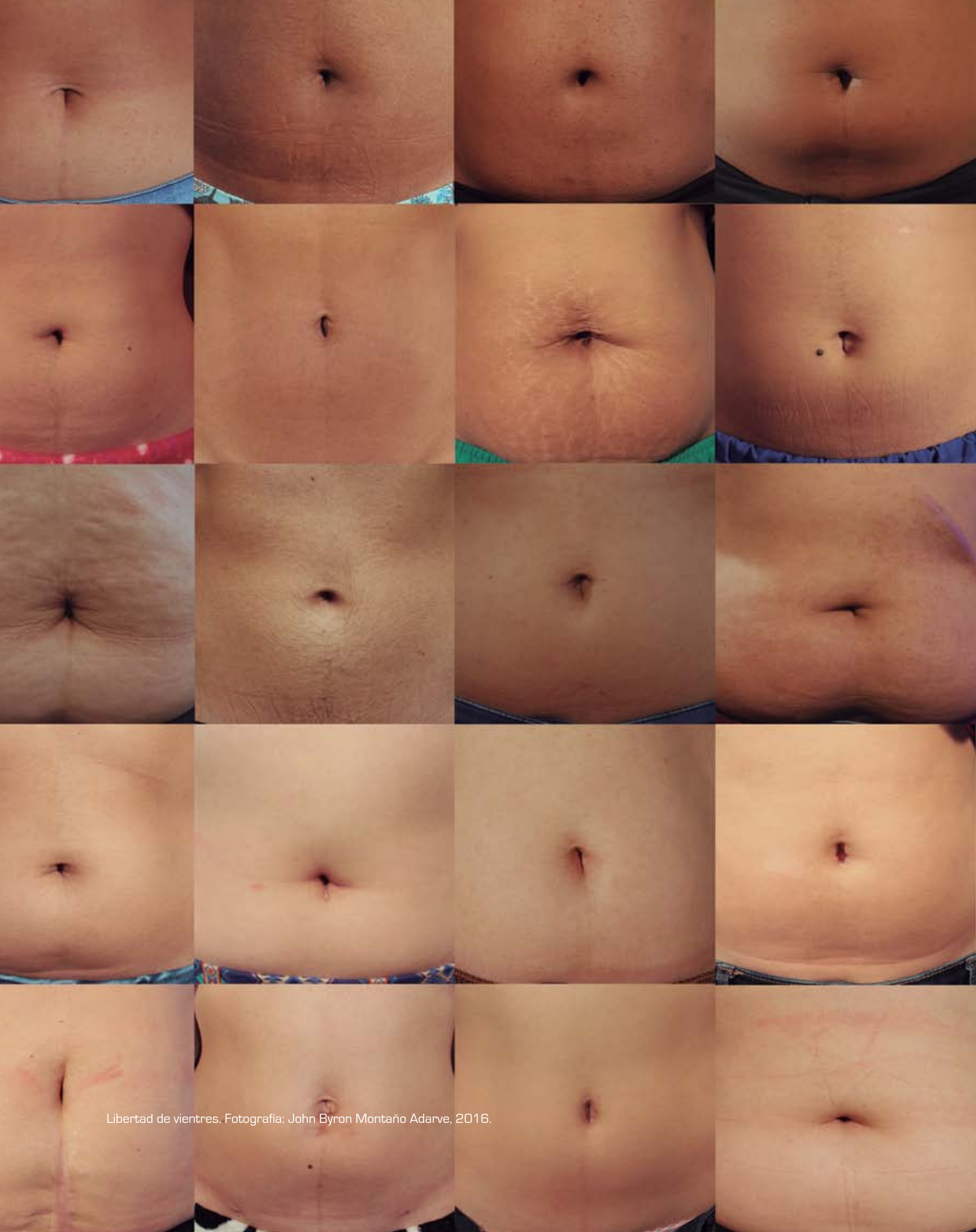


